\title{
Abstracts from the 18th Annual Scientific Conference of Montenegrin Sports Academy and 16th FIEP European Congress "Sport, Physical Education, Physical Activity and Health: Contemporary perspectives": Dubrovnik, Croatia. 8-11 April 2021
}

\author{
Edited by Dusko Bjelica', Stevo Popovic', Selcuk Akpinar², Dario Novak ${ }^{3}$ \\ Affiliations: 'University of Montenegro, Faculty for Sport and Physical Education, Niksic, Montenegro, ${ }^{2}$ Nevşehir Hacı Bektaş Veli University, Department \\ of Physical Education and Sports, Nevşehir, Turkey, ${ }^{3}$ University of Zagreb, Faculty of Kinesiology, Zagreb, Croatia
}

Correspondence: D. Bjelica, University of Montenegro, Faculty for Sport and Physical Education, Narodne omladine bb, Niksic, Montenegro, E-mail: dbjelica@ucg.ac.me

@MJSSMontenegro

MEETING ABSTRACTS FROM MSA-FIEP DUBROVNIK 2021 CONFERENCE

http://mjssm.me/?sekcija=article\&artid=501

Cite this article: Bjelica, D., Popovic, S., Akpinar, S., \& Novak, D. (2021). Abstracts from the 18th Annual Scientific Conference of Montenegrin Sports Academy and 16th FIEP European Congress "Sport, Physical Education, Physical Activity and Health: Contemporary perspectives": Dubrovnik, Croatia. 8-11 April 2021. Montenegrin Journal of Sports Science and Medicine, 10(S1), 5-19. doi: 10.26773/mjssm.210401

\section{Invited speakers}

\section{S1}

ECOLOGICAL APPROACH TO HIGH SCHOOL STUDENTS PHYSICAL ACTIVITY: THE MEANING OF ENVIRONMENTAL, INTERPERSONAL AND PERSONAL FACTORS

Brigita Mieziene ${ }^{1}$

'Lithuanian Sports University, Kaunas, Lithuania

Correspondence: Brigita Mieziene (brigita.mieziene@lsu.It)

Young people are not sufficiently physically active. The socio-ecological model (SEM) enables for a search of the modifiable factors in the specific populations, as it allows to consider factors laying on different levels of individuals' life as well as interplay of those factors. The aim of this study was to examine the direct and indirect associations of factors laying on different levels within SEM with high school students' leisure time moderate to vigorous physical activity (MVPA). This cross-sectional population-based study included 1386 students from 14 to 19 years old, mean 16.14. Physical activity, neighborhood physical activity recourses, neighborhood safety, social capital, physical activity motivation and sociodemographic factors were evaluated. Logistic regression, mediation and moderation analyses were performed predicting leisure MVPA. Greater social participation (OR 1.03 [1.01-1.05]), higher relative autonomy index
(OR 1.11 [1.06-1.15]) and male gender (OR 1.71 [1.13-2.57]) directly predicted sufficient physical activity. Any significant moderation effects ( $p>0.05$ ) of environmental characteristics were found for the relationship between social capital, motivation factors and MVPA. The evidence of positive indirect mediation effect was found in all five models for social capital components. Findings provide support for the direct and indirect pathways from social capital to MVPA. Future interventions should focus on strengthening physical activity motivation by encouraging the development of social network and social participation as well as family, neighborhood, and school social capital.

\section{S2 \\ PHYSICAL EDUCATION IN EUROPE: PRELIMINARY FINDINGS FROM THE 4TH WORLDWIDE SURVEY OF QUALITY PHYSICAL EDUCATION \\ Dario Novak ${ }^{1}$ \\ 'University of Zagreb, Faculty of Kinesiology, Zagreb, Croatia Correspondence: Dario Novak (dario.novak@kif.hr)}

This presentation draws from the 4th Worldwide Survey of Quality Physical Education (QPE). The Survey is being administered at both policy-level and at school-level by UNESCO and the International Federation of Physical Education (FIEP). The Survey

\footnotetext{
Received: 15 March 2021 | Accepted after revision: 13 April 2021 | First published online: 20 April 2021

(c) 2021 by the author(s). License MSA, Podgorica, Montenegro. This article is an open access article distributed under the terms and conditions of the Creative Commons Attribution (CC BY).
}

Conflict of interest: None declared. 
has been designed to assess quality physical education policy and practice, as well as to address basic data gaps. Data collected as part of this survey will inform the development of international indicators on QPE which aim to: a) enhance QPE policy-practice coherence between countries and regions; b) provide QPE datasets disaggregated by gender, disability, country/region and thematic area; c) promote data-driven investment in QPE (at national, regional and international levels). The purpose of this keynote presentation is to present the European perspective of school-level PE as well as developments since the last Survey.

\section{S3}

\section{ANTHROPOMETRIC PARAMETERS AS INDICATORS OF TOP SPORT - PROJECT OF FACULTY FOR SPORT AND PHYSICAL EDUCATION OF UNIVERSITY OF MONTENEGRO}

Jovan Gardasevic ${ }^{1,2}$, Dusko Bjelica ${ }^{1,2}$, Ivan Vasiljevic ${ }^{1,2}$, Bojan Masanovic ${ }^{1,2}$ ${ }^{1}$ University of Montenegro, Faculty for Sport and Physical Education, Niksic, Montenegro, ${ }^{2}$ Montenegrin Sports Academy, Podgorica, Montenegro Correspondence: Jovan Gardasevic (jovan@ucg.ac.me)

The aim of this project is to build a large database of anthropometric characteristics and body composition in elite athletes in different sports disciplines. In all measurements, we used the same battery of 11 variables evaluated anthropometric characteristics and body composition: body height, body weight, triceps skinfold, biceps skinfold, skinfold of the back, abdominal skinfold, upper leg skinfold, lower leg skinfold, body mass index, fat percentage and muscle mass. Today, as a result we have several thousand measured top athletes and the largest database of these variables in the region. Based on the obtained data, scientific papers are published in Web of Science. These papers are dealing with comparisons among athletes in the same or different sports disciplines, as well as making model characteristics in specific sports, since the subject of measurements were the best players in the world in their sports.

\section{S4}

\section{RENAISSANCE OF SPORTS VALUE AND INNOVATION OF PERSONNEL CULTIVATION MODE}

Bute ${ }^{1,2}$, Huang Huiqing ${ }^{1}$, Min Sicheng1, Meng $\mathrm{Di}^{1}$

${ }^{1}$ Hunan Normal University, Faculty for Sport and Physical Education, Hunan, China, ${ }^{2}$ Hunan Sports Industry Research Institute, Hunan, China Correspondence: Bu Te (616387696@qq.com)

General Secretary Xi Jinping attaches great importance to school physical education and physical health of teenagers. He proposed the "Four in one" as the new orientation of school physical education which specific objectives are: "Enjoy fun, Strengthen physique, Sanity personalities and Exercise will". "Four in one" is the role reorientation of School Physical Education objectives. It is the new connotation of the new position of school physical education, the change and Renaissance of sports value theory: from technology-oriented to culture-oriented, and the latest achievement and contemporary value of school physical education in China. The goal of this study is to discuss and expound the innovation of sports talent development mode and promote the research progress of physical education in China. Specific key words "value", "innovation", "personnel", "cultivation", "renaissance", "mode", and "sports" were used to search relevant electronic databases. The research was based on General Xi's exposition on physical education, extract relevant concept from his interviews and speeches. General Xi's "Four in one" theory is the best embodiment of the return of the value of physical education as well as the latest educational achievement in contemporary China. The return of sports value of physical education has influenced the personnel cultivation mode and the basic trend of school physical education reform. "Four in one" as the new orientation of the concept of physical education in China, which is a logical and scientific physical education methodology, a transformation of physical education research paradigm, and a conceptual innovation of personnel cultivation mode.

\section{Oral presentations}

\section{1}

\section{THE MEANING OF ATTITUDES TOWARDS PHYSICAL EDUCATION FOR HIGH SCHOOL STUDENTS' MOTIVATION AND REGULAR PHYSICAL ACTIVITY}

Arunas Emeljanovas' ${ }^{1}$, Brigita Mieziene' ${ }^{1}$, Laura Tumynaite' ${ }^{1}$, chiro Kawachi ${ }^{2}$ 'Lithuanian Sports University, Kaunas, Lithuania, ${ }^{2}$ Harvard University, School of Public Health, Boston, MA, United States of America Correspondence: Arunas Emeljanovas (arunas.emeljanovas@lsu.It)

For enabling pathways to health through behavior, attitudes towards physical education (PE) and motivation towards physical activity (PA) raise intense interest as the important determinants to reduce physical inactivity. The aim of this study is to investigate direct and indirect relationships among attitudes towards physical education and high school students' regular physical activity, exploring the role of motivation to be physically active as a mediator. It was hypothesized that regular physical activity will be related indirectly to affective and cognitive attitudes towards physical education through self-determined motivation for physical activity. Study included 919 high school students. Among them 44.6 percent were boys. The age of these students varied from 15 to 18 years, with the mean age of $16.26 \pm 1.29$. The attitudes towards physical education were measured by instrument contained 20 items anchored on two attitude components (enjoyment and usefulness). Regular PA was evaluated by several items from HBSC questionnaire. Motivation towards physical activity was measured by BREQ-2 questionnaire. Results show that controlling for gender, enjoyment in $\mathrm{PE}$ is related to intrinsic motivation, which is directly related to regular PA. Perception of usefulness in $\mathrm{PE}$ is related to identify behavior regulation and it in turn is associated with regular PA. While a motivation negatively predicts regular PA. Affective attitudes towards physical education enhance intrinsic PA behavior regulation, while cognitive attitudes raise identified PA behavior regulation. Both of these self-determined behavior regulations predict regular PA.

\section{$\mathrm{O} 2$}

\section{THE ROLE OF UNIVERSITIES IN COUNTRIES' SUCCESS IN ELITE SPORT}

Nadim Nassif ${ }^{1}$

${ }^{1}$ Notre Dame University - Louaize (NDU), Department of Psychology, Education and Physical Education, Zouk Mosbeh, Lebanon

Correspondence: Nadim Nassif (nnassif@ndu.edu.lb)

In most of the countries outside of North America, elite sport is mainly run by clubs and federations. This however, does not mean that universities have a minor role in elite sport. The goal of this study is to identify a general framework which explains the influence that universities have on the improvement of countries' results in elite sport. We have based our analysis on the World Ranking of Countries in Elite Sport (WRCES), which measures the performance of all the countries in all the sports recognized by the Global Association of International Sports Federations. We have then done a correlation between the 2014, 2015, 2016, 2017, 2018 and 
2019 editions of the WRCES with the population, Gross Domestic Product and scientific research output rankings of the same years. Results have shown that performance in elite sport has a weak correlation with population's size, a strong one with the Gross Domestic Product and a very strong one with research output. The universities, cradle of scientific research, have therefore a determinant role in countries' success in elite sport. Universities are the principal providers of the skills needed by coaches, medics, managers and physical education teachers, which are leading actors in the sport movement. They therefore have a major impact at all the levels of the sport pyramid: grassroots, youth and elite.

\section{O3}

\section{NUTRITIONAL ASSESSMENT OF FEMALE YOGA PRACTITIONERS WITH DIFFERENT LEVELS OF EXPERIENCE}

Stefan Kolimechkov ${ }^{1}$, Lubomir Petrov ${ }^{2}$, Deyana Vankova ${ }^{3}$, Deidre Douglas ${ }^{4}$ ${ }^{1}$ STK Sport, London, United Kingdom, ${ }^{2}$ National Sports Academy, Sofia, Bulgaria, ${ }^{3}$ Medical University Varna, Bulgaria, ${ }^{4}$ ron Philosophy Training, Altavista, VA, United States of America

Correspondence: Stefan Kolimechkov (dr.stefan.kolimechkov@gmail.com)

Yoga includes many components for a healthy lifestyle such as physical exercises, abstaining from tobacco, stress management and a low-fat diet. The aim of this study was to assess the nutrition of yoga practitioners and to compare it with international guidelines for a healthy diet. This study comprised 89 female yoga practitioners from Bulgaria. The nutrient intake was assessed by using a food frequency questionnaire based on the USDA National Nutrient Database. The relative intake of proteins, carbohydrates, fats, energy contribution of each nutrient, and the total daily energy intake and relative energy intake were calculated. The BMI of the yoga practitioners was near the lower normal limit $(18.5 \mathrm{~kg} / \mathrm{m} 2)$. Only 3 practitioners were overweight. The yoga practitioners consumed small amounts of pork and beef and $\sim 60 \%$ did not consume any meat at all. They consumed an average of $600 \mathrm{~g}$ of fruits and vegetables per day, which complies with the $400 \mathrm{~g}$ recommended by the WHO. Practicing yoga helps to maintain normal weight which is one of the prerequisites for a healthy lifestyle. The nutritional assessment of the yoga participants corresponded with the recommendations of the WHO and the American Cancer Society Guidelines for a healthy diet.

\section{O4}

\section{ASSOCIATION BETWEEN SEDENTARISM AND EMOTIONAL WELL-BEING ON CHILEANS DURING CONFINEMENT DUE TO COVID-19 PANDEMIC}

Rodrigo Gallardo-Rodríguez', Karen Gallardo-Rodríguez², Orlando Gallardo-Green ${ }^{3}$

'Universidad Católica de la Santísima Concepción, Facultad de Educación, Departamento de Ciencias del Deporte y Acondicionamiento Físico, Concepción, Bío Bío, Chile, ${ }^{2}$ Universidad de las Américas, sede Concepción, Concepción, Bío Bío, Chile, ${ }^{3}$ Universidad de Concepción, Facultad de Educación, Departamento de Educación Física, Concepción, Bío Bío, Chile

Correspondence: Rodrigo Gallardo-Rodríguez (rodgallardo@gmail.com)

Studies have shown that sedentarism is a risk factor to physical and mental health. Confinement due to the COVID-19 pandemic has had a significant impact on the increase in a sedentary lifestyle. This study aims to analyze whether sedentarism due to confinement in Chileans is related to levels of anxiety, depression, and self-perception of health 98 men and 184 women (age $=36.2 \pm 12.3$ ) participate. International Physical Activity Questionnaire (IPAQ-short form), an ad-hoc questionnaire with a Likert-type scale, was asked to evaluate how good they considered their health, and the Spanish version of the Hospital Anxiety and Depression Scale (HADS) were applied. The Spearman Rho coefficient was calculated to determine the relationship between the people's sedentarism and well-being, and self-perception of health. A significant correlation was found between people who spent more time sitting weekly with higher levels of anxiety $(\mathrm{p}=.015)$, depression $(\mathrm{p}<.001)$, and lower self-perception of health $(\mathrm{p}=.024)$. The findings suggest that sedentarism could affect people's well-being and self-perception of health. Thus, it is necessary to promote strategies that reduce sedentarism during the pandemic to avoid mental health problems.

\section{5}

\section{MODERN TRENDS IN STUDENTS' COGNITIVE HEALTH INDICATORS DURING THE EDUCATIONAL PERIOD}

Sergii Ivashchenko', Borys Grinchenko'

${ }^{1}$ Kyiv University, Faculty of Health, Physical Education and Sports, Kyiv, Ukraine

Correspondence: Sergii Ivashchenko (algis6274@hotmail.com)

Maintaining high indicators of students' cognitive health during their studies in higher education institutions is an important scientific problem, some aspects of which, unfortunately, remain insufficiently studied in our time. The purpose of this research was to study the dynamics of changes in the main indicators of the cognitive health, which are typical for most students, who are trained in institutions of higher education. In the course of research, the methods of pedagogical observation, medical control of health condition, interviews, questionnaires, and statistical processing of the obtained data were applied. This study involved 428 students from institutions of higher education in Kiev. During this study two groups of students (main and experimental) were formed. The process of teaching students of the main group was carried out in improved conditions and with the programs adapted to the individual cognitive abilities of students. The students of the control group were trained in normal conditions and with the use of standard curricula. As a result, all indicators of cognitive and mental health of students in the main group were higher than those of students in the control group. The data obtained during this study indicate that the level of mental and cognitive health of students who are trained in higher education institutions depends on the conditions, nature and intensity of the educational process.

\section{6}

\section{JOB SATISFACTION OF PHYSICAL EDUCATION TEACHERS IN SLOVAKIA}

Tibor Balga', Branislav Antala'

${ }^{1}$ Comenius University in Bratislava, Faculty of Physical Education and Sport, Bratislava, Slovakia

Correspondence: Tibor Balga (tibor.balga@uniba.sk)

Many studies have confirmed that job satisfaction is one of the important factors that maintain a high level of performance. The aim of this study was to analyze job satisfaction among physical education teachers in Slovakia. This was a cross-sectional intraindividual ex post facto research. 139 male and 173 female Slovak physical education teachers participated in this study, 165 of them were employed at primary schools and 147 of them worked at secondary schools. To get the empirical data, the method of questionnaire and interview was used. It has been shown that job satisfaction of physical education teachers in Slovakia are differentiated in terms of gender, but are not differentiated from the point of view of age and of the type of school. The analysis of data shows that male physical teachers working in schools have better job satisfaction than their female counterpart. The findings suggest that job satisfaction of physical education in Slovak teachers is low. This research was realized out within the proj- 
ect VEGA, No. 1/0523/19 „Telesná a športová výchova a jej kvalita a potenciál v podpore zdravia z pohladu žiakov, učitelov a rodičov“. ["Physical and Sports Education and its Quality and Potential in Promoting Health from the Perspective of Pupils, Teachers and Parents"].

\section{7}

\section{INCLUSION OF PRE-SCHOOL CHILDREN WITH SPECIAL NEEDS IN THE PHYSICAL ACTIVITIES}

Jelena Alic1, Donata Vidakovic Samarzija'

'University of Zadar, Department of Teacher and Pre-school Teacher Education, Zadar, Croatia

Correspondence: Jelena Alic (jcetinic@unizd.hr)

Physical activities are of great importance for the harmonious development of children with special needs. Those children must be provided with an inclusive environment by participating in all kind of physical activities. The aim of this research was to determine whether there is a difference in the attitudes and self-competence towards the inclusion of pre-school children with special needs in the physical activities between pre-school teachers and students of early and preschool education. The study was conducted on a sample of 65 preschool teachers and 49 students. The "Questionnaire of Attitudes towards Pre-school Inclusion" was used to assess attitudes and self-assessment of competencies related to the inclusion of children with special needs during physical activities. Concerning the results it can be concluded that there are no differences in attitudes towards the inclusion of pre-school children between students and pre-school teachers except for the one variable. Pre-school teachers compared to the students, have a more positive attitude about the socializing effect that results from inclusion of the children with special needs with other children. Furthermore, there are differences between students and preschool teachers concerning the results of their competence for work in inclusive groups. The findings suggest that teachers and students should improve their competence for inclusion of children with special needs.

\section{O8}

\section{PHYSICAL SELF-PERCEPTION OF PUPILS IN PE CLASSES - DIFFERENCES WITH REGARD TO GENDER AND NUTRITIONAL STATUS}

Donata Vidakovic Samaržija', Jelena Alic ${ }^{1}$

'University of Zadar, Department of Teacher and Preschool Teacher Education, Zadar, Croatia

\section{Correspondence: Donata Vidakovic Samarzija (dovidak@unizd.hr)}

Physical self-perception (PSP) is one of the factors that influence on the motivation for more frequent physical exercise. To examine the level of PSP of the primary school pupils in the Physical Education class (PE) and to determine differences in the dimensions of PSP with regard to gender and nutritional status. The study was conducted on a sample of 2834 th and 8 th grade pupils. PSP was examined based on an anonymous questionnaire by which the respondents assessed their coordination, sports competencies, strength, flexibility and endurance. Body mass index (BMI) was calculated as an indicator of nutritional status. The significance of differences in the dimensions of PSP with regard to gender and nutritional status were calculated. 4th graders in all dimensions of PSP have higher scores than 8 th graders. 8th male graders have significantly higher results in all dimensions than 8th female graders. 4 th male graders have higher results only in the dimensions of strength. 4th graders with normal BMI vs. overweight BMI have significantly higher results in the dimensions of coordination, flexibility and endurance, while 8th graders with normal BMI better assess only the dimensions of strength. Low level of PSP may be an obstacle to engaging in physical activity. The results of this research indicate risk groups that need strategies aimed to raising the level of PSP.

\section{O9 \\ EVALUATION OF BASIC MOTOR COMPETENCIES IN PRIMARY SCHOOL IN LUXEMBOURG}

Claude Scheuer ${ }^{1}$, Andreas Bund ${ }^{1}$, Sandra Heck' ${ }^{1}$, Christian Herrmann ${ }^{2}$ 'University of Luxembourg, Department of Education and Social Work, Institute for Teaching and Learning, Esch-sur-Alzette, Luxembourg, ${ }^{2}$ Zürich University of Teacher Education, Department for Movement and Sports, Zürich, Switzerland

Correspondence: Claude Scheuer (claude.scheuer@uni.lu)

To participate in the culture of human movement, it is indispensable for students to be in command of the necessary basic motor competencies (in German: Motorische Basiskompetenzen; MOBAK). For the implementation of the MOBAK approach in Luxembourg (MOBAK-LUX), we developed test instruments for preschoolers (-PS), first graders $(-1)$, third graders $(-3)$ and fifth graders (-5). These motor test series are conducted on a voluntary basis by interested schools and teachers at the beginning of each school year. All four test instruments consist of items in four dimensions: "locomotion", "object control", "moving in water" and "object locomotion". The results of the 2019 surveys indicate that a considerable proportion of students in all tested grades show low basic motor competence levels in at least one of the four competence areas. Passing less than two thirds of the basic test items in one area, these students show respective support needs: $65.6 \%$ of preschoolers $(\mathrm{N}=393), 44.9 \%$ of first graders $(\mathrm{N}=292), 18.1 \%$ of third graders $(\mathrm{N}=476)$ and $26.1 \%$ of fifth graders $(\mathrm{N}=257)$. The increasing interest in MOBAK-LUX shows that the implementation of competence-oriented test tasks has found acceptance among teachers and helps to identify students with support needs in certain areas of motor competence.

\section{0}

\section{THE CONSEQUENCES OF CANCELLED PHYSICAL EDUCATION CLASSES DURING THE COVID-19 PANDEMIC: THE TEACHERS' VIEW IN A EUROPEAN COMPARISON}

Andreas Bund', Sandra Heck', Claude Scheuer ${ }^{1}$

'University of Luxembourg, Department of Education and Social Work, Institute for Teaching and Learning, Esch-sur-Alzette, Luxembourg

Correspondence: Andreas Bund (andreas.bund@uni.lu)

Due to measures adopted by governments in European countries to contain the first wave of the Covid-19 pandemic, no physical education (PE) classes were taking place early this year. The present study was aimed at examining the consequences of this cancellation for the individual development of students from the teachers' perspective. An online questionnaire was distributed in a number of European countries, consisting of two sections: (1) The cancellation of PE classes and its consequences, and (2) the implementation of PE classes in compliance with the Covid-19 rules. The following results relate to the first-mentioned section. In total, 335 PE teachers (175 males; age: 2270 years) from 12 European countries completed the questionnaire. A clear majority expects a serious or rather serious impact on the students' development in the fields of motor performance (77.4\%), psychosocial well-being (84.7\%) and health (82.3\%). PE teachers in Luxembourg and Belgium consider the impact on students' motor development as less serious (66.0\% resp. 64.4\%) than teachers in Spain and Portugal (88.9\% resp. $87.8 \%)$. Although this study is solely focused on the teachers' view, the findings underline the importance of PE and support the decision of responsible authorities to further provide physical activities in school during the ongoing pandemic. 


\section{1}

\section{INCLUSIVE PRIMARY PHYSICAL EDUCATION: THE TEACHERS'} VIEW IN A EUROPEAN COMPARISON

\section{Sandra Heck', Claude Scheuer ${ }^{1}$}

'University of Luxembourg, Department of Education and Social Work, Institute for Teaching and Learning, Esch-sur-Alzette, Luxembourg Correspondence: Sandra Heck (sandra.heck@uni.lu)

The Erasmus+ project "Disentangling Inclusion in Primary Physical Education (DIPPE)" under the lead of the University of Luxembourg aims to provide information about the national value of inclusive physical education. The results are further on used for the development of an open resource platform for primary school teachers and their educators where information about inclusion and inclusive physical education is made available. To gather information about the national value of inclusive physical education, a survey among primary school teachers was conducted. Teachers in nine European countries $(\mathrm{n}=1168)$, including Luxembourg, were asked about the country-specific situation of inclusive physical education at primary schools. Compared to other European countries, the Luxembourgish teachers surveyed in the sample rate the importance of the subject "inclusive physical education" as generally less important for their country and for their respective school. Nevertheless, more than $80 \%$ of the respondents consider inclusive teaching to be "important" or "extremely important" in their own teaching practice in Luxembourg. Based on the results of the survey, it can be assumed that the planned web-based application, which shall function as a supportive tool by providing digital material for the inclusive teaching of physical education, constitutes a desired topic that is strongly linked to the teaching practice in schools and developed for the use in school settings.

\section{2}

\section{PHYSICAL EDUCATION AND HEALTHY LIFE}

Nenad Zivanovic', Zoran Milosevic'2, Veroljub Stankovic ${ }^{3}$, Nebojsa Randjelovic ${ }^{4}$, Kristina Pantelic Babic ${ }^{5}$

'University of Nis, Faculty of Sport and Physical Education, Nis, Serbia, ${ }^{2}$ University of Novi Sad, Faculty of Sport and Physical Education, Novi Sad, Serbia, ${ }^{3}$ University of Kosovska Mitrovica, Faculty of Sport and Physical Education, Leposavic, Serbia, ${ }^{4}$ University of Nis, Faculty of Sport and Physical Education, Nis, Serbia, ${ }^{5}$ University of Banjaluka, Faculty of Physical Education and Sport, Banjaluka, Bosnia and Herzegovina

Correspondence: Nenad Zivanovic (nenad.zivanovic46@gmail.com)

Physical education, as a part of physical culture, is a very important educational link. It is particularly important in an era characterized by fast technological advances and technicalism that is rapidly introducing people to virtual reality. We emphasize that physical education, with its knowledge ABOUT and FOR physical exercise, builds the basis for a healthy, active and long life. This is possible because the physical education, based on the anthropocentrism, sees physical exercise as a beneficial body activity necessary for man and stems from the relationship to a man as a person, not an individual. Theoretical analysis and test were used. Anthropological research conducted in Serbia and AP Vojvodina have confirmed that the number of people who regularly engage in physical exercise is decreasing. That is why we point out the importance of physical education, which, with its knowledge of how and why to exercise, builds the awareness of the necessity for physical exercise, as well as of the possibility of seeing every physical activity as physical exercise.
013

\section{THE DIFFERENCE BETWEEN TEACHERS' PERCEPTIONS AND TEST RESULTS OF BASIC MOTOR COMPETENCIES IN PRESCHOOL CHILDREN \\ Dana Masarykova' \\ ${ }^{1} T r n a v a$ University, Faculty of Education, Trnava, Slovakia \\ Correspondence: Dana Masarykova (dana.masarykova@truni.sk)}

Children in preschool age are very sensitive to learning new skills and an appropriate attitude to the development of basic motor competencies can be of large benefit for later motor development. However, we often witness lack of good assistance and learning opportunities in preschool education. The aim of this study is to present the level of basic motor competencies in preschool children and show the differences in the level of competencies and perceptions of teachers related to these competencies. We used the MOBAK KG test battery for preschool children $(n=121)$ to get the information on the level of basic motor competencies. An interview was used to get information on the perception of the competencies by kindergarten teachers $(n=9)$. The children achieved better results in self-movement than object movement, but the teachers expressed better results in object movement. The teachers expressed that the boys will be better in all the tasks, but the girls achieved better results in bouncing, balancing and rolling. A very low or low level of motor competence was achieved by $44 \%$ of children in object movement and by $36 \%$ in self-movement. The findings suggest that the teachers often have misperceptions on the level of motor competencies in preschool children. An objective assessment tool as MOBAK KG could help the teachers in identifying problematic areas in motor development and this could lead to more inclusive and more effective motor development process in preschool education.

\section{4}

\section{THE EFFECTS OF 12-WEEK TRAINING BETWEEN 12-15 YEARS OLD ATHLETE ON PHYSICAL PARAMETERS, COMPARISON OF SOCIAL SKILLS AND SPORT ORIENTATION LEVELS WITH NON-SPORTS TEENS}

Cevdet Tinazci', Huseyin Guneralp'

${ }^{1}$ Near East University, Faculty of Sports Sciences, Nicosia, Cyprus

Correspondence: Cevdet Tinazci (cevdet.tinazci@neu.edu.tr)

Sports is the best way to improve individuals in terms of physic, emotion and society, to achieve cooperation and team spirit and to gain individually to the society. This study aims to determine the importance of sports on social skills and sport orientation, also to determine the effects of 12 weeks training on some physical parameters of football players, who didn't have any obstacles in terms of health. A total of 81 subjects (12-15 years old) participated in the study. In order to determine some physical, social skills and sport orientation characteristics of sports and non-sports children, flexibility test, push-up test, shuttle test, stop long jump test, vertical jump test, flamingo balance test and augmentation test, 10,20,30 m sprint and ball speed tests, $20 \mathrm{~m}$ shuttle run test were used. Statistically significant differences were found in all tests except the gain orientation and target orientation which are the sub-dimensions of body weight test and fitness orientation inventory $(\mathrm{p}<0.05)$. As a result, it was observed that the 12-week exercise applied to the children who are actively involved in sports had a positive increase in the physiological and physical parameters. It has been observed that sports provide positive improvements in social skills and sport orientation levels of children. 


\section{5}

\section{PHYSIOLOGICAL EFFECTS OF TOPICALLY APPLIED COOLING GEL ON THE SKIN}

Ron Clijsen ${ }^{1,2,3,4}$, Skander Ouni $^{1}$, Peter Clarys ${ }^{1}$, Dirk Aerenhouts' ${ }^{1}$, Erich Hohenauer ${ }^{1,2,3,5}$

${ }^{1}$ University of Applied Sciences and Arts of Southern Switzerland, Department of Business Economics, Health and Social Care, Landquart, Switzerland, ${ }^{2}$ International University of Applied Sciences THIM, Landquart, Switzerland, ${ }^{3}$ Vrije Universiteit Brussel, Faculty of Physical Education and Physiotherapy, Department of Movement and Sport Sciences, Brussels, Belgium, ${ }^{4}$ Bern University of Applied Sciences, Department of Health, Berne, Switzerland, ${ }^{5}$ University of Fribourg, Department of Neuroscience and Movement Sciences, Fribourg, Switzerland Correspondence: Ron Clijsen (ron.clijsen@supsi.ch)

Topical application of cooling gels is widely accepted to reduce pain and to promote muscle recovery. Despite the wide use of cooling gels, scientific evidence for its efficacy is lacking and further research is needed. The aim of this RCT was to investigate the physiological effects of topically applied cooling gel on skin and muscle characteristics. After topical application of the cooling gel on the lower back of healthy women, skin temperature (infrared camera), the skin's micro perfusion (Speckle Laser), blood flow (Power Laser Doppler) and tissue oxygenation (near-infrared spectroscopy) were non-invasively measured at different depths every five minutes for one hour. After application of the cooling gel, skin temperature decreased $(\mathrm{p}<0.001)$ while skin blood flow was higher $(\mathrm{p}<0.001)$ throughout the whole protocol compared to the control area. Our results show that topically applied cooling gels do not only affect the skin surface temperature, but also blood flow in the papillary dermis. The results concerning the muscle remain inconclusive.

\section{6}

\section{POST-EXERCISE CWI FOR INTRAMUSCULAR TEMPERATURE CHANGES IN THE M. QUADRICEPS FEMORIS: A SYSTEMATIC REVIEW}

Erich Hohenauer ${ }^{1,2,3}$, Livia Freitag', Carlina Deflorin', Wolfgang Taube ${ }^{3}$, Ron Clijsen ${ }^{1,2,4}$

'University of Applied Sciences and Arts of Southern Switzerland, Clinical Exercise and Rehabilitation Science Group, Landquart, Switzerland, 2International University of Applied Sciences THIM, Landquart, Switzerland, ${ }^{3}$ University of Fribourg, Department of Neurosciences and Movement Sciences, Fribourg, Switzerland, ${ }^{4}$ Bern University of Applied Sciences, Department of Health, Berne, Switzerland

Correspondence: Erich Hohenauer (erich.hohenauer@supsi.ch)

High intensity exercise can lead to microscopic lesions in the muscle tissue, which are often treated with cold-water immersion (CWI). This review aims to investigate the effects of post-exercise CWI $\left(10^{\circ} \mathrm{C}, 10 \mathrm{~min}\right)$ on intramuscular temperature changes (IMTC) of the M. Quadriceps femoris at $1-3 \mathrm{~cm}$ depths in dependency of the subcutaneous adipose tissue thickness (ST) A systematic electronic database literature search was conducted until June 2020. A total of $\mathrm{n}=6$ studies met the pre-defined selection criteria. Maximum IMTC was $6.40^{\circ} \mathrm{C}$ with ST of $6.50 \mathrm{~mm}$ at a depth of 1 $\mathrm{cm}, 4.50^{\circ} \mathrm{C}$ with ST of $11.00 \mathrm{~mm}$ at $2 \mathrm{~cm}$, and only $1.61^{\circ} \mathrm{C}$ with ST of $10.79 \mathrm{~mm}$ at $3 \mathrm{~cm}$. No significant correlation between IMTC and ST was observed at a depth of $1 \mathrm{~cm}: \mathrm{r} 2=0.0$, at $2 \mathrm{~cm}: \mathrm{r} 2=-0.8$ and at $3 \mathrm{~cm}$ : $\mathrm{r} 2=-0.5$ (all $\mathrm{p}>0.05$ ). Post-exercise CWI decreases intramuscular temperature in the M. quadriceps femoris. Beside skinfold thickness, additional key variables affect the magnitude of IMTC in post-exercise CWI.
017

\section{THE DEVELOPMENT OF WAIST CIRCUMFERENCE MEANS} VALUES IN ALBANIAN CHILDREN AGED 6.5-15 YEARS

Juel Jarani', Keida Ushtelenca', Florian Muca' ${ }^{2}$, Andi Spahi' 'Sports University of Tirana, Faculty of Movement Sciences, Tirana, Albania, ${ }^{2}$ Albanian Sports Science Association, Tirana, Albania Correspondence: Juel Jarani (jueljarani@gmail.com)

Abdominal obesity is associated with many risk factors for cardiovascular disease and type 2 diabetes. Waist circumference is a measure of obesity and as such can be a very important indicator in children as a predictor of metabolic syndrome. This paper attempts to provide a more details investigation regarding the current level and comparison of waist circumference growth with increasing ages. A representative sample of elementary and secondary Albanian school children from the Balkan region (Albania, Kosovo, North Macedonia and Montenegro), approximately in proportion to their age distribution were participated. The sample population consisted of 18023 children ( 9028 boys, 8995 girls) with ages ranging between 6.5 and 15 years. Mean waist circumference increased with age in both boys and girls. The results of this investigation show that boys have significant higher values $(\mathrm{p} \leq 0.05)$ compared with girls in elementary school (7-11 yrs.). No significant changes by gender were observed in secondary school children (11.5-15 yrs.). One of the more significant finding to emerge from this study is that the highest value of waist circumference increase for boys is $3.5 \mathrm{~cm}$ (12.5-13.5 years old; $\mathrm{p}=0.000)$ while for girls is $4.3 \mathrm{~cm}(11.5-12.5$ years old; $\mathrm{p}=0.000$ ). The findings of this study will help clinical and possibly epidemiological use for identifying earlier central obesity in children.

\section{8}

\section{PRIORITISING ADOLESCENT MOTOR COMPETENCE IN PHYSICAL EDUCATION: EVALUATING THE EFFECTIVENESS OF PROJECT FLAME}

Wesley O'Brien', Till Utesch², Sarahjane Belton ${ }^{3}$, Michael J. Duncan ${ }^{4}$, Lisa E. Bolger ${ }^{1,5}$, Fiona C. Chambers ${ }^{6}$, Diarmuid Lester ${ }^{1}$

'University College Cork, School of Education, Sports Studies and Physical Education Programme, Cork, Ireland, ${ }^{2}$ University of Münster, Institute of Educational Sciences, Münster, Germany, ${ }^{3}$ Dublin City University, School of Health and Human Performance, Dublin, Ireland, ${ }^{4}$ Coventry University, Research Centre for Applied Biological and Exercise Sciences, Coventry, United Kingdom, ${ }^{5}$ Cork Institute of Technology, Department of Sport, Leisure and Childhood Studies, Cork, Ireland, ${ }^{6}$ University College Cork, School of Education, Cork, Ireland

Correspondence: Wesley O'Brien (wesley.obrien@ucc.ie)

The current study aimed to evaluate the effectiveness of Project FLAME (Fundamental and Functional Literacy for Activity and Movement Efficiency), a school-based physical education (PE) intervention targeting the improvement of adolescent motor competence. Using a pre-post research design as part of a non-randomized controlled trial, a sample of 363 participants (mean age: $14.04+0.89$ years old) were recruited from three mixed-gender, sub-urban schools in Cork. Primary outcome measures evaluating the effectiveness of the Project FLAME intervention included the assessment of ten FMS, as well as seven functional movements. Linear mixed models were used to analyse the effect of the intervention with two main effects (treatment and time), and their hypothesised interaction. Intervention effects across time for overall gross FMS ( $p=.002$ ) were observed, when compared with a control group. The intervention group also significantly improved their overall functional movement composite score $(p=.001)$, however, a statistically significant treatment-time interaction effect was not found between groups. A movement culture which 
prioritises adolescent motor competence in the PE curriculum can improve students' movement abilities in the Irish secondary school landscape.

\section{9}

\section{VALIDITY OF WEARABLE MONITORS AND SMARTPHONE APPLICATIONS IN MEASURING ADOLESCENTS' STEPS AND DISTANCE}

Manolis Adamakis ${ }^{1}$

'University College Cork, School of Education, Cork, Ireland

Correspondence: Manolis Adamakis (manosadam@phed.uoa.gr)

To objectively measure physical activity, new sophisticated monitors and applications have been developed, and it is necessary to conduct accuracy evaluations of the latest products. The purpose of the present study was to examine the criterion validity of wearable monitors and smartphone applications in adolescents, during outdoor walking and running. Thirty-eight adolescents $(15.3 \pm 2.0$ years) were fitted with Garmin Forerunner 310XT, Garmin Vivofit, Medisana Vifit, and smartphones running the Runkeeper, Runtastic, Sports Tracker (GPS), Pedometer, Accupedo, Pedometer and Pedometer 2.0 (accelerometer) applications. They walked and ran $1.2 \mathrm{~km}$ for each trial and two researchers counted all steps with a digital tally counter (criterion measure). Validity was evaluated by comparing each device with the criterion measure using mean absolute percentage errors (MAPE) and Bland-Altman plots. Results showed that MAPE were low for Forerunner 310XT and GPS applications for distance estimation (2.27\%-9.73\%) in both conditions, and significantly higher for the accelerometer monitors and applications (6.92\%-39.02\%). Vivofit $(\mathrm{MAPE}=6.51 \%)$ and Vifit $(\mathrm{MAPE}=6.66 \%)$ accurately estimated the number of steps during walking, however only Vivofit (MAPE $=3.95 \%)$ was accurate during running. All accelerometer applications had higher MAPE for step counting (9.87\%-40.26\%). The findings suggest that GPS monitors and applications are accurate tools for distance counting, while accelerometer monitors and applications provide higher errors. Vivofit provides accurate estimation for step counting in both conditions, and Vifit is valid during walking. Accupedo is the only accelerometer application with an acceptable error.

\section{O20}

SURFING IN PHYSICAL EDUCATION: AN EDUCATION PROJECT Carlos Cobo-Corrales ${ }^{1}$, José Manuel Castanedo-Alonso ${ }^{2}$, Mikel PérezGutiérrez 1

'University of Cantabria, Faculty of Education, Santander, Spain, 2University de Barcelona, Faculty of Education, Barcelona, Spain

Correspondence: Carlos Cobo-Corrales (carlos.cobo@alumnos.unican.es)

Surfing is a sport with an important socioeconomic and cultural impact. Several studies have also corroborated the relevance of implementing surfing in educational context for improving motivation and participation in PE classes, but no works describe how to do it. The aim is to describe an education project in PE for promoting the learning of surfing in secondary school students through the development of a successful educational intervention A bibliographic review was performed for extracting pedagogical and didactical recommendations regarding the effective inclusion of surfing in PE. The emerging pedagogical model 'Interactive Challenges with Shared Responsibility' was used for planning and developing this project. Throughout a school year, students learn the necessary skills to enjoy surfing and be able to practice it outside of school. The learning process is developed in a dialogic learning environment in which high expectations, solidarity and equitable learning are encouraged. The pedagogical approach is divided in three progressive phases attending to their contents and facilities. Firstly, bal- ance tasks are developed in the sports hall. Secondly, buoyancy and swimming skills are acquired in the pool. Thirdly, surfing skills and techniques are learnt in the sea. This project orientates PE teachers for the successful inclusion of surfing in their classes, providing a comprehensive planning with pedagogical orientations.

\section{O21}

\section{ASSESSMENT OF MAXIMUM FORCE, VELOCITY AND POWER: INFLUENCE OF REGRESSION MODEL AND APPLIED LOADS} Predrag Bozic ${ }^{1,2}$

${ }^{1}$ Serbian Institute of Sport and Sports Medicine, Belgrade, Serbia, ${ }^{2}$ University of Montenegro, Faculty for Sport and Physical Education, Niksic, Montenegro

\section{Correspondence: Predrag Bozic (predrag.bozic@rzsport.gov.rs)}

The study aimed to explore the concurrent validity of maximum mechanical outputs (force - F0, velocity - V0 and power - PMAX) obtained from force-velocity (F-V) and power-velocity (P-V) relationships and compare if the results are affected by the number of experimental points. Twenty three physically active male participants performed 6-second sprints on a cycling ergometer at the eight randomized loads. Multiple-point method (5, 6, 7, 8, 9, 10, $11 \%$ of body mass) were used to model the linear F-V and polynomial P-V relationships. Additionally, two-point (5 and $11 \%$ of body mass) and three-point protocol $(6,8,10 \%$ of body mass) were used to model the linear F-V and polynomial P-V relationships, respectively. For the P-V relationships, the intercept was set to zero value. The high concurrent validity $(r>0.91)$ was obtained between the two regression models regardless if they applied on multiple, two, or three-point loads. Parameters F0, V0 and PMAX obtained from different regression methods or protocols did not differ $(\mathrm{p}>0.05)$. These results support using the linear two-point or polynomial three-point method as an efficient and less prone to fatigue procedures. They provide a highly valid assessment of maximal muscular capacities expressed through F0, V0 and PMAX.

\section{O22}

\section{ASSOCIATION OF LABORATORY AND FIELD BALANCE TEST}

Nikola Foretic ${ }^{1}$, Vladimir Pavlinovic ${ }^{1}$, Sime Versic

'University of Split, Faculty of Kinesiology, Split, Croatia

Correspondence: Nikola Foretic (nikolaforetic@gmail.com)

Balance can be defined as ability to maintain body center of gravity within the surface of the support. It has crucial role in humans' everyday activities but also in sport. However, there is insufficient knowledge regarding balance field testing. The main aim of this study was to determine association between Biodex laboratory balance test and $\mathrm{Y}$ balance field test. The participants in this study were 12 students (7 males, 5 females) of Faculty of Kinesiology in Split, Croatia. The set of variables included anthropometric measures (body height, body weight, and body mass index), two laboratory balance tests conducted on Biodex balance system (Postural stability test, Limits of stability test) and field balance test (Y balance test). The correlation between observed variables was calculated by Pearson's product moment test. No significant correlations were found between $Y$ balance test and both Postural stability test ( $\mathrm{r}=-0.06$ for left and for right leg 0.02 , respectively) and Limits of stability test $(\mathrm{r}=-0.06$ and $\mathrm{r}=0.02)$. The results of this study indicate that $\mathrm{Y}$ balance test is not a good measure of balance in well-trained individuals. Authors hypothesize that $\mathrm{Y}$ balance test performance is greatly influenced by lower extremity strength and mobility. There is a obvious need for the construction and validation of new field tests to assess the level of balance in recreational and professional athletes. 


\section{O23}

\section{MOTIVATION AND PERSONALITY TRAITS OF CROATIAN NATIONAL TEAM FEMALE ROWERS}

Mladen Marinovic

${ }^{1}$ University of Split, Faculty of Kinesiology, Split, Croatia

Correspondence: Mladen Marinovic (marin@kifst.hr)

The aim of this paper is to examine the relations and structure of motivation and personality traits of female rowers. 60 female rowers, who have competed in international regattas as part of the Croatian national team for the past 20 years, have completed the following tests: Motives of general and sporting achievement of Havelka and Lazarević as well as Eysenck's personality questionnaire. The SPSS program was used for statistical data processing. The results of Kaiser-Meyer-Olkin's Measure of Sampling Adequacy (.684) and Bartlett's Test of Sphericity (Sig. <.001) indicate that the data are suitable for conducting factor analysis. Factor analysis extracted two factors explaining $60.35(43.57+16.78) \%$ of the variance. Oblimin rotation with Kaiser normalization, the first factor is saturated with Motive of sports achievement (.863), Psychoticism $(-.791)$, positive emotional reactions in sports achievement (.780), and Motive of general achievement (.776). The second factor is explained by Neuroticism (.787) and Extraversion (-.739). Component Correlation Matrix was (-.163). The results of the research suggest the appearance of two factors that present Croatian female rowers in the observed area. The first factor can be called the Motivation for Achievement factor. Two personality traits, Neuroticism and Extraversion, which explain the second factor, can be viewed within the framework of the Galen-KantWund scheme, which states that the second factor can be called the Temperament factor.

\section{O24}

\section{SHOOTING SPEED DIFFERENCES BETWEEN PLAYING POSITIONS IN TOP LEVEL HANDBALL}

Vladimir Pavlinovic ${ }^{1}$, Nikola Foretic ${ }^{1}$, Sime Versic ${ }^{1}$

'University of Split, Faculty of Kinesiology, Split, Croatia

Correspondence: Vladimir Pavlinovic (vladimirpavlinovic@gmail.com)

Scoring the goal in handball is performed by shooting action. Shooting speed is one of the most important attacking elements that influences successful performance in handball. Anyhow, there is a lack of scientific data considering shooting speed between different playing positions. PURPOSE: The main aim of this study was to determine differences in shooting speed between playing positions in top level male handball players. METHODS: Data used in this study was collected from official match reports of European handball championship held in Austria, Norway and Sweden 2020. 784 shoots were analyzed and variables included were shooting speed and playing position. Shooting speed was collected with iBall (SELECT, Denmark), with a built-in chip that tracks and distributes data in real time (Kinexon, Germany). Differences between playing positions were calculated with Kruskal-Wallis test. RESULTS: Significant difference in shooting speed was noticed between playing positions (Chi-Square $=67,34$ ). Posthoc analysis reveled that line positions (wings and pivots) shoot significantly slower than outfield positions. No differences were noticed between wings and pivots, nor between left, right and center back. CONCLUSION: On the first sight, results of the study are biomechanically contradictable since faster shoots are from longer distances. Anyway, results could be easily explained if game dynamic is analyzed. Namely, line shoots are executed from narrow angle situations which more often require creative and wise, than strong shooting performance.
$\mathrm{O} 25$

INFLUENCE OF ANTHROPOMETRICS AND POWER ON SPECIFIC REACTIVE AGILITY PERFORMED IN DOMINANT SIDE AT YOUNG BASKETBALL PLAYERS

Damir Sekulic ${ }^{1}$, Nedim Sicic ${ }^{2}$, Nikola Foretic ${ }^{1}$

${ }^{1}$ University of Split, Faculty of Kinesiology, Croatia, ${ }^{2}$ University of Zenica, Bosnia and Herzegovina

Correspondence: Damir Sekulic (dado@kifst.hr)

Agility is one of the most important abilities that determines successful performance in basketball. It appears in reactive and non-reactive form. Knowledge of agility dependence on other abilities and morphological features can help basketball practitioners in developing efficient training program. The main aim of this study was to determine influence of morphology and power on basketball specific reactive agility. The participants in this study were 58 elite young basketball players from Bosnia and Herzegovina $(\mathrm{BH}=188.5 \pm 8.1 \mathrm{~cm}$; $\mathrm{BW}=77.2 \pm 11.5 \mathrm{~kg} ; \mathrm{AGE}=17.4 \pm 1.1$ year). Testing variables included 10 anthropometric measures, 12 basic fitness tests and 2 basketball specific agility tests. The correlation between observed variables was calculated by Pearson's product moment correlation. Influence of morphological and fitness variables on agility was calculated by forward stepwise regression analysis. RA-DOM had eleven significant correlations, while NER-DOM had sixteen significant correlations with basic morphology and motor variables. Significant influence on RA-DOM and NER-DOM was determined by standing reach and sprint on 20 meters. The results of the study revealed importance of explosiveness and longitudinal body dimensions on specific basketball reactive agility executed in dominant side of performance. Authors connect this finding with test structure and demands. Test simulate individual defensive action in which basketball player has to reach the ball on cone after explosive and agile reaction.

\section{O26}

\section{GRIP FORCE LATERALIZATION PROFILE OF WOMEN VOLLEYBALL PLAYERS}

Selcuk Akpinar', Kursat Ozcan', Ugur Odek'

${ }^{1}$ Nevsehir Haci Bektas Veli University, Department of Physical Education and Sport, Nevsehir, Turkey

Correspondence: Selcuk Akpinar (selcukbos@gmail.com)

In many sports, less lateralized performances are preferred and can be one of the key factors to the success. Athletes in volleyball most of the time use their both hands for passing, blocking and digging. Correctly executing these technical skills are essential both for defense and offense in volleyball. Thus, applying the similar force when executing these skills is a requirement for successful performance. The aim of the study is to examine grip force lateralization profile of professional women volleyball players. Ten professional right-handed women volleyball players voluntarily participated to the study. Two dependent variables calculated to test grip force lateralization, max grip force and max grip rate of force development (RFD). Paired-Samples t-test was conducted for each dependent variable. The statistical analyses for both variables showed significant results, $\mathrm{t}=-5.82 \mathrm{p}<.05$ and $\mathrm{t}=-6.03 \mathrm{p}<.05$, respectively (max grip force non-dominant hand $=$ $342.07 \pm 66.04$ and max grip force dominant hand $=378.84 \pm 60.08$ $\mathrm{N}$; max grip RFD non-dominant hand $=2321.79 \pm 409.27$ and $\max$ grip RFD dominant hand $=2708.66 \pm 543.25 \mathrm{~N} / \mathrm{s}$ ). . Players displayed a lateralization pattern for both dependent variables. Symmetrical applications should be performed in trainings. The playing positions should be also considered as the players mostly use their dominant hand for spiking. Individual data showed that two players in the setter position displayed no lateralization. Thus, trainers should pay attention to have no lateralized players for this position. 


\section{7}

\section{MONTENEGRIN SPORT ASSOCIATIONS ON SOCIAL MEDIA -} QUALITY OF PERFORMANCE ASSESSMENT

Suncica Rogic ${ }^{1}$, Milica Vukcevic', Milica Muhadinovic', Julija Cerovic Smolovic ${ }^{1}$

${ }^{1}$ Univesity of Montenegro, Faculty of Economics, Podgorica, Montenegro Correspondence: Suncica Rogic (suncica.rogic@hotmail.com)

The aim of this study is to assess the quality of performance of Montenegrin national sport associations on Facebook. Sport is recognized as an activity of public interest and social media is one of the main sources of information nowadays. Given that social media in sport has delivered a new style of communication, authors will try to evaluate the engagement with the fans and the general public, by using the FAI methodology. This methodology involves the analysis of three components: popularity (25\%), interactivity (40\%) and content (35\%). Each of the criteria is evaluated depending on the importance of the indicator on a scale from $0 \%$ to $100 \%$. Coefficient value closer to $100 \%$ indicates higher quality of performance on Facebook. The results of our paper show the differences between the three categories of Olympic sports in Montenegro, taking into account their performance on Facebook. Social media, as a marketing tool can enhance the positioning of national sport associations by creating a meaningful connection with the fans and the public. Additionally, this connection may strengthen the feeling of devotion to the national team of Montenegro and incentivize younger generations to start training and competing. This study demonstrates which associations use this channel to portray their sport and results, with the aim of promoting sport and healthy lifestyle.

\section{$\mathrm{O} 28$}

\section{EFFECTS OF DIFFERENT RECOVERY TIMES ON INTERNAL AND} EXTERNAL LOAD DURING SMALL-SIDED GAMES IN SOCCER Luis Branquinho', Ricardo Ferraz ${ }^{1,2}$, Mário C. Marques ${ }^{1,2}$

'University of Beira Interior, Department of Sport Sciences, Covilhã, Portugal, ${ }^{2}$ Research Centre in Sports, Health and Human Development, Vila Real, Portugal

Correspondence: Luís Branquinho (luis_branquinho@outlook.pt)

The ability to maintain a high intensity of exercise in several repetitions of exercises depends essentially on the recovery from repetitions of previous exercises The aim of this study was to identify the effects of different recovery times on internal and external load during soccer small-sided games in soccer. Twenty professional male semi-professional soccer players participated in the study, performing the same exercise (5-a-side game format) continuously (1 $\mathrm{x} 18 \mathrm{~min})$ and repeatedly / fractionated $(3 \times 6 \mathrm{~min})$ with different recovery times $(30 \mathrm{~s}, 1 \mathrm{~m}, 1 \mathrm{~m} 30 \mathrm{~s}$ and $2 \mathrm{~m}$ ). The results reveal that the manipulation of the recovery times induced differences in internal and external load, and for the same total duration time, the external and internal load indicators tend to reveal higher values during the fractionated method particularly with short moments of recovery time. The application of small-sided games in soccer with different recovery times induce varying responses in training load.

\section{O29}

\section{BILATERAL STRENGTH ASYMMETRY IN ELITE YOUTH SOCCER} PLAYERS IN THE DIFFERENT AGE CATEGORIES

Maros Kalata' ', Tomas Maly', Mikulas Hank', Jakub Michalek'

${ }^{1}$ Charles University, Faculty of Physical Education and Sport, Sport Research Center, Prague, Czech Republic

Correspondence: Maros Kalata (kalata@ftvs.cuni.cz)

The prevalence of strength asymmetry as a negative factor for the health of athletes is increasingly being researched in the field of sports science. This study aimed to determine the level of bilateral muscle strength asymmetry (BA) for knee extensors (KE) in youth elite soccer players of different age categories (AC). The analyzed sample (n $=80$ ) consisted of youth elite soccer players of AC U12-U16. The maximum peak muscle torque of $\mathrm{KE}$ in the lower limbs during concentric muscle contraction with a low angular velocity of $60^{\circ} \mathrm{s}-1$ was measured with an isokinetic dynamometer. The analysis revealed significant differences $(\mathrm{p}<0.05)$ in BA between U14 and U16 (16.5 \pm $12.73 \%$ vs. $5.44 \pm 5.65 \%)$. The percentage of players with BA higher than $10 \%$ increased from the U12 to U14 up to $30 \%$ which was the highest value in all groups. Increased BA of KE in elite soccer occurred in the earlier period of career (U12-U14 categories) may be related to accelerated growth in adolescence and the dominant-sided character of movement performance. Therefore, we recommend starting diagnostics of strength asymmetry from the early age of the training process and maintaining more attention to optimizing the training load due to the higher incidence of BA.

\section{O30}

RELATIONSHIP OF MAXIMAL AEROBIC CAPACITY AND MATCH PHYSICAL PERFORMANCE IN ELITE YOUTH SOCCER PLAYERS

Jakub Michalek', Tomas Maly', Maros Kalata', Egon Kunzmann'

${ }^{1}$ Charles University, Faculty of Physical Education and Sport, Sport Research Center, Prague, Czech Republic

Correspondence: Jakub Michalek (jak.michalek@seznam.cz)

Aerobic fitness is important for footballers in terms of match load. Players have to cover the high distance in high-intensity running with repetitive movement action with high acceleration and deceleration. The aim of the study was to find out the relationship between internal and external load performance indicators with the maximal aerobic capacity (VO2max) in first division football players. Totally fifteen male players (age $=17.9 \pm 0.9$ years, body height $=177.3 \pm 6.7 \mathrm{~cm}$, body weight $=71.4 \pm 7.4 \mathrm{~kg}$ ) were tested by Intermittent recovery test level 1 (YYIR1). Following match load parameters were correlated to VO2max: high metabolic load distance (HMLD), average heart rate (HRavg), and total distance covered (TDC) in official matches $(n=10)$. The matches were divided into three time periods: T1 (0-45 minutes), T2 (70-90 minutes), T3 (0-90 minutes). The results of the study revealed the highest correlation between TDC and VO2max $(r=0.808, p=0.000)$ in T1 and T3 $(r=0.627, p=0.012)$. Significant correlation between has been also found between HMLD and VO2max $(r=0.602, p=0.017)$ in $\mathrm{T} 2$ and $\mathrm{T} 3(\mathrm{r}=0.543, \mathrm{p}=0.037)$. The results of the present study confirm the relevance of $\mathrm{VO} 2 \mathrm{max}$ on distance-covered parameters in first division soccer players. HMLD parameter had a significant relationship with maximal aerobic capacity during the last $20 \mathrm{~min}$ utes of the match, which is important for maintaining high physical performance over the match.

\section{O31}

\section{CORRELATES OF PHYSICAL ACTIVITY DURING THE COVID-19 PANDEMIC AMONG ADOLESCENTS FROM THE CROATIAN COASTAL REGION}

Barbara Gilic ${ }^{1,2}$, Mateo Blazevic ${ }^{1}$, Ivan Peric ${ }^{3}$

'University of Split, Faculty of Kinesiology, Split, Croatia, ${ }^{2}$ University of Zagreb, Faculty of Kinesiology, Zagreb, Croatia, ${ }^{3}$ University of Osijek, Faculty of Dental Medicine and Health, Osijek, Croatia

Correspondence: Barbara Gilic (barbaragilic@gmail.com)

The COVID-19 pandemic affected the changes in physical activity levels (PAL). The purpose of this study was to determine the correlates of PAL during the COVID-19 pandemic among adolescents. This research included 209 adolescents aged 15-17 years from Split, Croatia ( 89 boys, 120 girls). They were tested on anthropometrics, 
and fitness status (predictors). The PAL (assessed by the Physical Activity Questionnaire for Adolescents) was evidenced before and during the lockdown and was observed as criteria. Pearson's correlation coefficients and multiple regression were used to evaluate the associations between predictors and criteria. In the total sample, significant correlations were found between aerobic endurance and baseline PAL ( $r=0.37$ ), aerobic endurance and follow-up PAL $(\mathrm{r}=0.34)$, and sprint $100 \mathrm{~m}$ and baseline to follow-up difference PAL $(r=-0.23)$. However, when separated by gender, previous correlations were significant only for boys. Better aerobic endurance determined baseline PAL, while better sprint determined greater PAL decline as a result of the lockdown. Results evidenced that aerobic endurance and sprinting are determining the PAL before and during the lockdown. Future studies investigating other correlates of PAL are warranted, in order to create interventions for maintaining adequate PAL during COVID-19 and similar crises.

\section{$\mathrm{O} 32$}

\section{CORRELATES OF GENERIC AND SPORT SPECIFIC AGILITY IN PROFESSIONAL FUTSAL PLAYERS}

\section{Ivan Zeljko', Toni Modrić2 , Damir Sekulić2}

'University of Mostar, Faculty of Science and Education, Mostar, Bosnia and Herzegovina, ${ }^{2}$ University of Split, Faculty of Kinesiology, Split, Croatia

Correspondence: Toni Modric (toni.modric@yahoo.com)

Agility is an important determinant of success in futsal. This study aimed to examine associations between physiological and anthropometric characteristics, and futsal specific agility tests among professional futsal players. Participants of this study were 75 professional futsal players (all males, age: $25.1 \pm 5.1$ years, body height: $182.3 \pm 6.2 \mathrm{~cm}$, body mass: $80.8 \pm 10.4 \mathrm{~kg})$. Variables included anthropometrics [body height $(\mathrm{BH})$ and mass $(\mathrm{BM})$, body fat percentage (BF)], generic tests of physiological capacities [5- and 10-m sprints, countermovement jump (CMJ), broad jump (SBJ), 20-yard test (20Y), reactive strength index (RSI)], and futsal-specific tests of change of direction (CODS) with and without dribbling the ball, and futsal specific tests of reactive agility (RAG) with and without dribbling the ball. Results demonstrated that $20 \mathrm{Y}$ was correlated to anthropometrics (BM: $r=0.46 ; \mathrm{BF}: \mathrm{r}=0.63$ ) and conditioning variables (CMJ: $\mathrm{r}=-0.39$; RSI $=-0.46$; SBJ: $\mathrm{r}=-0.46$; $5 \mathrm{~m}$ sprint: 0.37 ; $10 \mathrm{~m}$ sprint: $\mathrm{r}=0.4)$. CODS was significantly affected by $\mathrm{BM}$ and $\mathrm{BF}$, while RAG was significantly affected only by BF (all $\mathrm{p}<0.01$ ). These findings suggest that (i) generic agility measured by $20 \mathrm{Y}$ was influenced with physiological and anthropometric characteristics of the players; (ii) specific futsal agility (CODS \& RAG) was influenced only with anthropometric characteristics.

\section{O33 \\ DIFFERENCES IN STUDENTS BODY COMPOSITION AFTER AN OUTDOOR ACTIVITY PROGRAM}

Andelko Simic', Edin Mujanovic ${ }^{2}$, Amra Nozinovic Mujanovic ${ }^{2}$, Alma H. Salihovic ${ }^{3}$, Mijo Curic ${ }^{4}$

${ }^{1}$ Medical high School, Osijek, Croatia, ${ }^{2}$ University of Tuzla, Faculty of Physical Education and Sport, Tuzla, Bosnia and Herzegovina, ${ }^{3}$ Gullvivan Primary School, Gislaved, Sweden, ${ }^{4}$ Josip Juraj Strossmayer University of Osijek, Faculty of Education, Department of Kinesiology, Osijek, Croatia

Correspondence: Andelko Simic (andelkosimic1990@hotmail.com)

Regular physical activity is widely recognized for playing a major role in regulating energy balance and body composition. The application of the outdoor activity program during summer vacations, camping or staying in sports camps aims to in- crease the level of daily physical activity and raise the level of awarenes among participants about the benefits of physical activity practicated in leisure time among participants. The aim of this study was to determine the differences in body composition in students caused by practicing outdoor activity program. The assessment of body composition for this research was conducted on the 30 male students, on the first day and after the end of the experimental program. The results of the variables used in this study show statistically significant differences at the level of significance $p<0.01$ and $p<0.05$ in 3 out of 6 treated variables, which means that the implemented program of outdoor activity produced significant partial quantitative changes in some variables. The data obtained in this research are of great importance to everyone responsible for the transfer of knowledge and positive developmental effects of physical exercise.

\section{Poster presentations}

\section{P1}

\section{MONTENEGRIN PLATFORM FOR INNOVATION IN SPORT}

Stevo Popovic ${ }^{1,2}$, Dusko Bjelica ${ }^{1,2}$, Sanja Pekovic ${ }^{3}$, Radenko Matic ${ }^{4}$ 'University of Montenegro, Faculty for Sport and Physical Education, Niksic, Montenegro, ${ }^{2}$ Montenegrin Sports Academy, Podgorica, Montenegro, ${ }^{3}$ University of Montenegro, Faculty of Tourism and Hotel Management, Kotor, Montenegro; ${ }^{4}$ University of Novi Sad, Faculty of Sport and Physical Education, Novi Sad, Serbia

Correspondence: Stevo Popovic (stevop@ucg.ac.me)

It is well-known that modern organizations clearly stand out as leaders in their industries have one common factor that brings them together around the fact they are successful, and that is they are all largely committed to innovation. This applies to the sports too. An empirical research was conducted with the aim of determining a research analysis of links between the sports sector, sports industry and knowledge organizations and innovation in Montenegro. Seventy-five subject representatives of sports organizations were randomly assigned as a sample, while Community Innovation Survey (CIS) was applied, and descriptive statistics were employed to test the hypothesis. This study confirmed that there is significant potential for improving innovation in sports in Montenegro. Policy makers and other stakeholders, including sports administrators and other sports leaders, should increase the ability of sports organizations to innovate in sports. This research has been done within national project under the title "Montenegrin Platform for Innovation in Sport" that was approved by Ministry of Science in Montenegro (No.03/1-062/20-263/2 from 28 April 2020), as well as in line with the SHIINE COST Action's objectives (CA18236).

\section{P2 \\ LEADING SPORTS INNOVATION LABORATORY FOR THE WESTERN BALKANS}

Radenko Matic ${ }^{1}$, Stevo Popovic ${ }^{2,3}$, Sanja Pekovic ${ }^{4}$, Ivana Milovanovic ${ }^{1}$ 'University of Novi Sad, Faculty of Sport and Physical Education, Novi Sad, Serbia, ${ }^{2}$ University of Montenegro, Faculty for Sport and Physical Education, Niksic, Montenegro, ${ }^{3}$ Montenegrin Sports Academy, Podgorica, Montenegro, ${ }^{4}$ University of Montenegro, Faculty of Tourism and Hotel Management, Kotor, Montenegro

Correspondence: Radenko Matic (radenkomatic@uns.ac.rs)

It is the fact that sport is known to be a dynamic and fast-growing sector with an underestimated macroeconomic impact. In addition, the fact that the share of gross value added (GVA) related to sport in total GVA in the EU varies from $1.76 \%$ to $3 \%$ in the broad sports 
sector, while total employment in the EU generated by sporting activities is 7.3 million and this is equivalent to $3.5 \%$ of total employment in the EU. These data confirm that sport is an important economic sector in the EU and plays a significant role in national economies. This analysis and significant data was preceded by the valuable work of experts in sports science and sports innovation across the EU, while in the Western Balkans it was significantly neglected. Hence, any gathering within PSI labs to generate innovation in the subject area, especially because sport can play an important role in a number of major societal challenges, such as physical in activity, sustainable development and educational gaps. From this reason, the goal of this study was to briefly describe an established methodology and criteria for the "Leading Sports Innovation Laboratory for the Western Balkans". This research has been done in line with the SHIINE COST Action's objectives (CA18236).

\section{P3}

\section{LIFESTYLE FACTORS CONTRIBUTING TO PREVENTION OF SARCOPENIA IN OLDER PEOPLE: A SYSTEMATIC REVIEW}

Nebojsa Nesic ${ }^{1}$, Vesna Seper ${ }^{1,2}$

'College of Applied Sciences "Lavoslav Ruzicka", Vukovar, Croatia, 'University of Novi Sad, Faculty of Sport and Physical Education, Novi Sad, Serbia

Correspondence: Nebojsa Nesic (nnesic@vevu.hr)

Sarcopenia is defined as the age-related decline in skeletal muscle mass and function which may lead to falls, hospitalization, mobility limitations, poor quality of life and increased risk of death in older people. Purpose is to identify lifestyle factors, with respect to nutrition and physical activity, contributing to prevention of sarcopenia in older people. Specific key words "elderly“, „supplementation“, „muscles“, „sarcopenia“ were used to search relevant electronic databases, such as BioMed Central, BMJ Journals, PubMed and CINAHL with full text. Studies that fit the inclusion criteria from 2015 and later, and describing lifestyle, exercise, nutrition in advanced age were reviewed. Results showed although diet and physical activity are important for muscle maintenance these requirements are not always met, aerobic or resistance exercise can be strenuous, especially if there are underlying health issues. Interventions that combine physical activity and nutritional supplementation may be helpful in prevention of malnutrition, muscle mass loss and mobility limitations and contribute to upholding and improving physical function.

\section{P4}

\section{IMPACT OF BASIC-MOTOR SKILLS ON SITUATIONAL EFFICIENCY} OF SPIKE STRENGHT IN MONTENEGRIN VOLLEYBALL PLAYERS

Danilo Bojanic ${ }^{1}$, Milovan Ljubojevic', Dragan Krivokapic' ', Pavle Malovic', Erol Vrevic ${ }^{1}$

'University of Montenegro, Faculty for sport and physical Education, Niksic, Montenegro

Correspondence: danilo.bo@ucg.ac.me (danilo.bo@ucg.ac.me)

Modern volleyball game is a very popular sport, as some kind of recreational activity, but also as a professional sport, which is played by a very large part of both male and female populations. The goal of this study is to determine the influence of the basic motor abilities on the situational motor ability of the spike strength. The selected respondents represent the population of top volleyball players competing in the First Volleyball League of Montenegro. This research was conducted on a sample of 75 female volleyball respondents who were in the active training process: "Budućnost", "Morača", "Rudar", "Galeb", and "Luka Bar". Situation-motor space was estimated with the variable of the spike strength. The partial influence of basic-motor skills on the strength of the spike predominantly belongs to the explosive strength of the arms and shoulder girdle, which is needed for fast, strong and efficient spike, as well as the explosive strength of the lower extremities. So we can conclude that all the large muscle groups, both the trunk and the lower and upper extremities, are engaged in the power of the spike in the game. Spike is a pronounced element of attack that is used in the final actions of scoring points.

\section{P5}

\section{MONTENEGRIN FIRST LEAGUE FOOTBALL PLAYERS' GENERAL KNOWLEDGE IN SPORTS NUTRITION EVALUATION} Erol Vrevic', Mirko Mikic', Amel Mekic ${ }^{2}$

'University of Montenegro, Faculty for Sport and Physical Education, Niksic, Montenegro, ${ }^{2}$ University of Sarajevo, Faculty of Sport and Physical Education, Sarajevo, Bosnia and Herzegovina

Correspondence: Erol Vrevic (vrevicerol@gmail.com)

Faster recovery, the ability of longer and better training, as well as performance increase in the competition itself are some of the positive characteristics of reduced sport nutrition. Therefore, sports nutrition plays a very important role in modern sports. The aim of this study is evaluation of the Montenegrin first league football players' general knowledge in the field of sports nutrition. This study includes 33 professional football players of the Montenegrin first league, aged 18 to 40 . A standardized closed-ended survey questionnaire was used to assess general knowledge in the field of sport nutrition. For the purposes of this study, the questionnaire was modified and translated into Montenegrin. The data obtained by the research were processed by descriptive statistical procedures. Statistical analysis was accomplished by SPSS 23.0 software. In this questionnaire $45.9 \%$ answers were correctly, while $54.1 \%$ were incorrect or unanswered. These results show poor general knowledge in sports nutrition. This, as well as other studies done on the topic of knowledge in the field of sport nutrition among Montenegrin athletes, showed an insufficient level of knowledge. Sport nutrition is one of the most important links when it comes to success in sports, therefore, it is necessary to pay more attention to it in order to raise the national sport to a higher level.

\section{P6}

\section{METHODS OF DETERMINATION OF ANAEROBIC THRESHOLD IN SWIMMER'S TRAINING}

Dragan Krivokapic', Danilo Bojanic' ${ }^{1}$, Milovan LJubojevic ${ }^{1}$

'University of Montenegro, Faculty for Sport and Physical Education, Niksic, Montenegro

Correspondence: Dragan Krivokapic (dr.agan@t-com.me)

The most accurate way to determine a swimmer's anaerobic threshold is to measure lactate levels directly from a blood sample taken during progressive exercise. This is a relatively expensive and for most athletes a rather uncomfortable method of measuring lactate. Several relatively precise ways to determine the anaerobic threshold without taking blood samples have been constructed in recent years. Frequently used methods for determining the anaerobic threshold in swimmer's training are: the Conconi method, the method based on determining the maximum pulse, the assessment of the ventilatory oxygen equivalent etc. The Conconi method is increasingly used in the training practice of swimmers because it is a reliable and easily applicable method for determining the anaerobic threshold. This method is based on the fact that at a certain, relatively high intensity of exercise, the linear correlation between speed and heart rate ceases. The point at which the linear flow of a function becomes exponential coincides with the anaerobic threshold and represents the highest intensity that can be supported by predominantly aerobic energy sources and that can be maintained 
over a longer period of time. The nonlinear increase in heart rate is evidence that anaerobic energy sources predominate above the anaerobic threshold.

\section{P7}

\section{BODY HEIGHT AND ITS ESTIMATION UTILIZING ARM SPAN MEASUREMENTS IN MALE AND FEMALE ADOLESCENTS FROM CENTRAL REGION IN MONTENEGRO}

Marina Vukotic ${ }^{1}$, Zoran Milosevic ${ }^{2}$

'University of Montenegro, Faculty for Sport and Physical Education, Niksic, Montenegro, ${ }^{2}$ University of Novi Sad, Faculty of Sport and Physical Education, Novi Sad, Serbia

Correspondence: Marina Vukotic (marina.vukotic82@gmail.com)

The goal of this study was to examine the height of male and female in the central region, as well as the ratio of body height and arm span as an alternative assessment of body height, which should vary from region to region in Montenegro. The sample in this research comprised 467 adolescents, all of whom were in their final year of high school (217 male and 250 female) among the population of Montenegrin adolescents. The stature and arm span measurements were taken according to the ISAK protocol, and the data were analyzed statistically. Linear regression analysis determined the prediction of arm span on the criterion variable a body height at the significance level of $\mathrm{p}<0.05$. Thereby, we obtained the coefficient of determination, the multiple correlation coefficients, the partial correlation coefficient, the regression, $\mathrm{t}$-test and standardized beta coefficient. The research study confirmed that arm span reliably predicts stature in both genders of Montenegrin adolescents and revealed a very useful finding for physical anthropologists and experts from related fields. It was confirmed that there is a correlation between arm span and body height (males: $48.4 \%$, females: $42.2 \%$ ) in the central region in Montenegro. Therefore, arm span proves to be a reliable predictor for the actual body height estimates.

\section{P8}

\section{MODEL OF TRAINING FOR MARATHONS TAKING INTO ACCOUNT FEATURES OF THE MECHANISM OF ENERGY SUPPLY OF MUSCLE ACTIVITY}

Vladislav Bakayev', Alexander Bolotin'

${ }^{1}$ Peter the Great St. Petersburg Polytechnic University, Institute of Physical Education, Sports and Tourism, St. Petersburg, Russia

Correspondence: Vladislav Bakayev (vlad.bakaev@gmail.com)

At present, the existing system of training marathon runners for competitions is characterized by insufficient consideration of the peculiarities of the mechanism of energy supply of muscular activity in the training process. Its main drawback is the general approach to training marathon runners. Coaches in their work with marathon runners are guided exclusively by their personal experience of preparing athletes for competitions. This does not effectively develop general and speed endurance in marathon runners. The aim of the study is to show experimentally that the means and methods of training marathon runners, taking into account the peculiarities of the mechanism of energy supply of muscular activity, play a significant role in increasing the effectiveness of preparation for competitions, which helps athletes to achieve higher results in the training process and at competitions. The study proposed a model of training marathon runners taking into account individual features of the mechanism of power supply of muscular activity, as well as a variety of specialized tasks for the development of tempo and speed endurance. In the course of the study, it was found that training sessions, taking into account the peculiarities of the mechanism of energy supply of muscle activity, have a higher efficiency. The proposed training model has proven to be effective. In the process of testing this model, athletes achieved higher results in the training process and in competitions.

\section{P9}

INCREASE OF STATOKINETIC STABILITY IN SKIERS BASED ON NORMOBARIC HYPOXIA IN COMBINATION WITH TRAINING OF MUSCLES OF THE CERVICAL SPINE

Alexander Bolotin ${ }^{1}$, Vladislav Bakayev ${ }^{1}$

'Peter the Great St. Petersburg Polytechnic University, Institute of Physical Education, Sports and Tourism, St. Petersburg, Russia

Correspondence: Alexander Bolotin (vlvbaks@gmail.com)

The high-speed and maneuverable movement of skiers along the track is accompanied by the impact on their body of angular, linear, centripetal accelerations. It has been established that the excessive impact of these dynamic accelerations when moving along the track leads to the emergence of pronounced vestibulo-somatic, vestibulo-vegetative and vestibulo-sensory reactions, which worsen the functional state of athletes and negatively affect their well-being. The aim of the study is to increase the level of statokinetic stability in skiers. Skiers of the experimental group used normobaric hypoxia training in combination with training the muscles of the cervical spine for a month in the preparatory period for the competition. The subjects of the control group used traditional exercises to increase the level of statokinetic resistance. As a result of the studies, it was found that the skiers of the experimental group significantly increased the tolerance time for the continuous cumulation of Coriolis accelerations. At the same time, a decrease in the severity of negative vestibulosensory, vestibulo-vegetative, vestibulosomatic reactions was noted. In addition, the skiers of the experimental group showed positive dynamics of the static stabilometric test during the complex functional computer stabilography. The results obtained make it possible to recommend the course use of normobaric hypoxia in combination with training the muscles of the cervical spine to increase the statokinetic stability of skiers.

\section{P10 DIFFERENCE IN BODY FLUID BEFORE AND AFTER TRAINING IN YOUNG JUDOKAS OF BOTH SEXES}

Amel Mekic ${ }^{1}$, Pavle Malovic ${ }^{2}$, Erol Vrevic ${ }^{2}$, Izet Bajramovic', Faris Rasidagic ${ }^{1}$ 'University of Sarajevo, Faculty of Sport and Physical Education, Sarajevo, Bosna and Herzegovina, ${ }^{2}$ University of Montenegro, Faculty for Sport and Physical Education, Niksic, Montenegro

Correspondence: Amel Mekic (amelmekic21@gmail.com)

Inadequate fluid intake leads to dehydration of the organism, which resulted in a reduction in psychophysical performance and health of athletes, therefore it is very important to take care of adequate hydration of the body. The aim of this research was to evaluate body fluid due to non-consume of the fluid during training, and to emphasize the importance of regular hydration in young judokas of both gender. This study included 65 judokas (8-13 years old) of both gender. The variables used to assess loss of body fluid during training were body weight (BW) and total body water (TBW). In this study respondents did not consume fluid during training. The data in this study was collected using the TANITA scale (model BC-418 MA). In this research was used descriptive statistical procedure, and the differences between the initial and final measurement assessed with the t-test with statistical significance of $p<0.05$. BW loss after training was $0.74 \mathrm{~kg}$ in boys and $0.64 \mathrm{~kg}$ in girls, and TBW $0.8 \mathrm{~kg}$ in boys and $0.12 \mathrm{~kg}$ in girls. A statistically significant difference between the initial and final measurements $(p<0.01)$ was found in both variables. Also, boys lost a statistically significantly more of TBW during training compared to girls $(\mathrm{p}<0.05)$. This research 
confirms that inadequate fluid intake during training significantly affects the loss of BW and TBW, which can have a many of negative consequences, both for sport performance and health.

\section{P11}

\section{APPLICATION OF DIDACTIC GAMES WITH A HOLISTIC APPROACH IN PRESCHOOL EDUCATION AND SCIENCE IN THE REPUBLIC OF NORTH MACEDONIA}

Zorica Stankovska' ${ }^{1}$ Marjan Malcev ${ }^{1}$

'University of Ss Curil and Methodius, St. Kliment Ohridski Faculty of Pedagogy, Skopje, Republic of North Macedonia

Correspondence: Zorica Stankovska (zoricakostovska.stankovska@ gmail.com)

The cognitive, emotional and motor characteristics of preschool children determine the didactic approach in the realization of the provided contents. To analyze the curriculum for early learning and development in order to discover which contents are suitable for realization by applying didactic games with a holistic approach, to determine the effects of teachers' attitudes and opinions through the implementation of the didactic games with a holistic approach. Keywords "holistic", "preschool education", "motor characteristics". The research was conducted by researchers-professors at the Faculty of Pedagogy "St. Kliment Ohridski". The research was conducted during one academic year. The central and dispersion parameters were calculated for each applied variable in the research. To determine the differences in the arithmetic means of the two groups of respondents, a T-test was applied. Based on the results obtained from the research we can say that although most variables deviate from the normal distribution, it is necessary to highlight that this deviation does not give a negative effect on the final results. According to the data, it can be concluded that the games that applied the holistic approach in the early development of children had a relatively small statistically sig nificant difference in the process of preschool education.

\section{P12}

\section{HANDBALL TEACHING EFFECTS ON MOTORIC SKILLS OF PRIMARY SCHOOL FEMALE STUDENTS}

Milovan Ljubojevic' ${ }^{1}$, Danilo Bojanic

'University of Montenegro, Faculty for Sport and Physical Education, Niksic, Montenegro

Correspondence: Milovan Ljubojevic (milovan.lj@ucg.ac.me)

Modern curriculum seeks to increase the number of weekly hours of physical activity through the elective subject Sports for athletes. The aim was to determine the effects of the elective course - Handball, on the motor skills of female students. The study was conducted for one school year on the sample of total 39 female students, divided into two groups. Control group consisted of students who attended only physical education classes. Experimental group, in addition to physical education classes, attended additional two classes of volleyball during a week. Motoric space was monitored through 8 variables of Eurofit battery tests, as follows: flamingo, hand tapping, seated forward bend (modified functional reach test), long jump, lay - sit for 30", pull-up endurance and pin running on $10 \times 5 \mathrm{~m}$. After the conduced study, the students of the control group had better results in 7 out of total 8 motoric tests. No statistically significant results, were recorded in the pullup endurance test. The students of the experimental group achieved better results in 7 of total 8 tests. The improvement was not recorded only in the seated forward test, which monitors as an ability. The analysis of the results confirmed that the teaching of physical education gives certain effects in the motoric space, but that the additional elective physical activities did not give the expected additional effects.
P13

TRAJECTORIES IN ANTHROPOMETRIC CHARACTERISTICS AND NUTRITION STATUS OF MONTENEGRIN ADOLESCENTS FROM THE MUNICIPALITY OF BERANE IN PERIOD FROM 1979 TO 1987

Dusko Bjelica ${ }^{1,2}$, Jovan Gardasevic ${ }^{1,2}$, Srdjan Redzepagic ${ }^{3}$, Bojan Masanovic ${ }^{1,4}$ 'University of Montenegro, Faculty for Sport and Physical Education, Niksic, Montenegro, ${ }^{2}$ Montenegrin Sports Academy, Podgorica, Montenegro, ${ }^{3}$ Université Côte d'Azur, GREDEG, Nice, France; ${ }^{4}$ Montenegrosport, Podgorica, Montenegro

Correspondence: Dusko Bjelica (sportmont@t-com.me)

The existence of a secular trend in the Montenegro is indisputable, while in order to determine the rate of change in certain periods, it is necessary to collect more data. This study aimed to consolidate body height, body weight, body mass index and nutrition status data of the entire young male population from the Municipality of Berane in order to estimate trajectories in ahead mentioned variables from 1979 to 1987 . The sample of respondents includes 8740 young males divided into nine groups according to their year of birth (respondents born between 1961 and 1969). The sample of variables includes body height, body weight, body mass index (calculated based on two previous measures) and nutrition status, which was presented based on BMI standardized categories (underweight, normal weight, pre-obese, obese). The descriptive statistics were expressed as a mean and standard deviation for each variable; the analysis of nutrition status was done based on body mass index (underweight, normal weight, pre-obese, obese), while post-hoc test with ANOVA were employed to explore differences between the means. The results showed that a secular trend in the observed study period is visible regarding body height and body weight, while is not visible for the body mass index and nutrition status. The contribution of this study is reflected in the fact that allows insight in newer published data for mentioned period, and in this Municipality, which can significantly help to follow the secular trend in all Montenegro.

\section{P14}

\section{TRENDS IN ANTHROPOMETRIC CHARACTERISTICS AND NUTRITION STATUS OF MONTENEGRIN ADOLESCENTS FROM THE MUNICIPALITY OF BIJELO POLJE IN PERIOD FROM 1979 TO 1987}

Bojan Masanovic ${ }^{1,2}$, Dusko Bjelica ${ }^{1,3}$, Zoran Milosevic ${ }^{4}$, Jovan Gardasevic ${ }^{1,3}$ 'University of Montenegro, Faculty for Sport and Physical Education, Niksic, Montenegro, '2Montenegrosport, Podgorica, Montenegro, ${ }^{3}$ Montenegrin Sports Academy, Podgorica, Montenegro, ${ }^{4}$ University of Novi Sad, Faculty of Sport and Physical Education, Novi Sad, Serbia Correspondence: Bojan Masanovic (bojanma@ucg.ac.me)

Previous studies suggest that secular trend in the world, including in Montenegro, is undeniably present, however in order to determine the rate of these changes in certain periods, additional data collection is necessary. This study aimed to consolidate body height, body weight, body mass index and nutrition status data of the entire young male population from the Municipality of Bijelo Polje in order to estimate trends from 1979 to 1987. The sample of respondents includes 10954 young males divided into nine groups: 1267 respondents born in 1961, 1356 respondents born in 1962, 1591 respondents born in 1963, 615 respondents born in 1964, 994 respondents born in 1965, 1227 respondents born in 1966, 1356 respondents born in 1967, 1118 respondents born in 1968, and 1430 respondents born in 1969. The measurement sample includes body height, body weight, and body mass index calculated based on two previous measures. The descriptive statistics were expressed as a mean and standard deviation for each variable, while the analysis of nutrition status was done based on body mass index (underweight, 
normal weight, pre-obese, obese). The results showed that a secular trend in the observed study period is not visible regarding body height, body weight and body mass index. The contribution of this study is reflected in the fact have been published data that did not exist for this period and this Municipality, which can significantly help to follow the secular trend in all Montenegro.

\section{P15}

\section{A COMPARISON STUDY ON DIFFERENCES WITH AGE FOR ANTHROPOMETRIC AND PHYSICAL ABILITIES IN GIRLS' VOLLEYBALL PLAYERS IN ALBANIA}

Altin Martiri', Florian Mema'

${ }^{1}$ Sports University of Tirana, Faculty of Movement Sciences, Tirana, Albania Correspondence: Altin Martiri (ustinfostudent@gmail.com)

The aim of this study was to find out the trend of improvement and differences with age of anthropometric and physical abilities in girls' volleyball players in Albania. Participants on this study were $(\mathrm{N}=67)$ volleyball players from three age categories as follows; kids (10-13 yrs.) $\mathrm{N}=21$, cadet (14-16 yrs.) $\mathrm{N}=22$, and junior (16-18 yrs.) $\mathrm{N}=24$. Measurement for anthropometrics and physical abilities were assessed. Multiple comparisons- LSD post hoc analysis showed results for anthropometrics: body height (kids vs cadet $11.5 \mathrm{~cm}$ increase $\mathrm{p}=$ 0.001 , cadet vs junior $6.3 \mathrm{~cm}$ increase $\mathrm{p}=0.045$ ), body weight (kids vs cadet $10.2 \mathrm{~kg}$ increase $\mathrm{p}=0.008$, cadet vs junior $9.4 \mathrm{~kg}$ increase $\mathrm{p}=$ 0.010 ), waist circumference (kids vs cadet $0.4 \mathrm{~cm}$ increase $\mathrm{p}=0.895$, cadet vs junior $6.3 \mathrm{~cm}$ increase $\mathrm{p}=0.019)$. Analysis also for physical abilities showed; push-ups (kids vs cadet 2.9 count improvement $\mathrm{p}=0.105$, cadet vs junior 0.9 count improvement $\mathrm{p}=0.699$ ), curl up (kids vs cadet 1.8 count improvement $\mathrm{p}=0.245$, cadet vs junior 1.1 count improvement $\mathrm{p}=0.583$ ), standing long jump (kids vs cadet $36 \mathrm{~cm}$ increase $\mathrm{p}=0.000$, cadet vs junior $17.7 \mathrm{~cm}$ increase $\mathrm{p}=$ 0.008 ). Final results show statistical increase between age categories for body weight, height and stranding long jump while for the other measurement no significant improvement was find mostly.

\section{P16}

\section{CORRELATION OF SPEED WITH STRENGTH AND POWER IN YOUTH BASKETBALL PLAYER}

Andi Spahi', Rando Kukeli ${ }^{2}$

${ }^{1}$ Sports University of Tirana, Faculty of Movement Sciences, Tirana, Albania, ${ }^{2}$ Sports University of Tirana, Faculty of Physical Activity and Recreation, Tirana, Albania

Correspondence: Andi Spahi (andispahi@gmail.com)

The strength, power and the speed are the most important abilities in basketball, either than technique \& tactics elements. The goal of this study is to find out the correlation of speed with strength and power in youth male basketball player. 42 youth male basketball players (age 16-18 years, mean 17.2 yrs.) were tested for speed (sprint $10 \mathrm{~m}$ and $30 \mathrm{~m}$ distance), strength and power (push up 30 s, curl up 30s, standing long jump, vertical jump). Correlation of speed (sprint $10 \mathrm{~m})$ with strength of upper limb is $\mathrm{p}=0.04(\mathrm{r}=-0.70)$ and speed (sprint $30 \mathrm{~m}$ ) with strength of upper limb is $\mathrm{p}=0.05$ ( $\mathrm{r}=-$ $0.63)$. The correlation of speed with core strength, power of lower limb is not statistical correlated ( $\mathrm{p} \geq 0.05$ ). The data showed that there is correlation between speed with upper body strength.

\section{P17}

\section{A TWO YEAR MONITORING AND COMPARING STUDY IN BODYBUILDERS ANTHROPOMETRICS PARAMETERS IN ALBANIA Rando Kukeli ${ }^{1}$, Andi Spahi ${ }^{2}$}

${ }^{1}$ Sport University of Tirana, Faculty of Physical Activity and Recreation,
Tirana, Albania, ${ }^{2}$ Sport University of Tirana, Faculty of Movement Sciences, Tirana, Albania

Correspondence: Rando Kukeli (rando_kukeli@hotmail.com)

The aim of this study to monitor and compare the anthropometric parameters in bodybuilders in Albania for 2 consecutive years. The test instrument used were circumference measurements which consist of neck, shoulder, and chest. The participants of this study were 92 athletes participating in the Albanian National Bodybuilding \& Fitness Championship of 2017 and 2018 divided into the categories Junior \& Senior Bodybuilding and Junior \& Senior Fitness. The result from in depended sample $t$ test for 2-year comparison (2017-2018) showed that circumference for the shoulder (category bodybuilding- junior male) was statistical different with $11 \mathrm{~cm}$ improvement $(\mathrm{p}=0.014)$, circumference for the chest (category bodybuilding- junior male) was statistical different with $6.6 \mathrm{~cm}$ improvement $(\mathrm{p}=0.018)$ and circumference for the chest (category fitness- senior male) was statistical different with $5.1 \mathrm{~cm}$ improvement $(p=0.012)$. Therefore, it may be concluded that despite the two categories bodybuilding- junior male and fitness- senior male, the other categories had no difference from 2017 to 2018 for the three circumference measurement (neck, shoulder and chest).

\section{P18}

\section{A COMPARISON STUDY ON ANTHOPOMETRIC PARAMETERS} BETWEEN U17 AND U19 YOUTH AGES IN FOOTBALL

Florian Mema' ${ }^{1}$, Altin Martiri ${ }^{1}$

'Sports University of Tirana, Faculty of Movement Sciences, Tirana, Albania Correspondence: Florian Mema (ustinfostudent@gmail.com)

Monitoring and recognizing the current state of anthropometric parameters are of particular importance to have a high performance and quality of sports in football. The purpose of this study is to compare anthropometric parameters between U17 and U19 youth ages in football. On this study were participated 53 youths (boys) that were part of football teams in two different categories; U17- N= 26 , mean age 16.5 years and $\mathrm{U} 19-\mathrm{N}=27$, mean age 18.2 years. Anthropometric measurement were taken for body height, weight and skinfold measurement (triceps, scapula and calf). Data comparison for body weight and height found no statistical significance between two age categories. Also no statistical difference were shown for three skinfold measurement assessed in this study between two age categories. Results from this study revealed that there were no difference in anthropometric parameter for body height, weight and skinfold thickness (triceps, scapula and calf) between U17 and U19 male youth footballers.

\section{P19}

\section{BODY MASS INDEX AS AN INDICATOR OF OBESITY IN FEMALE ADOLESCENTS IN MONTENEGRO}

Ivan Vasiljevic' ${ }^{1}$, Dusko Bjelica' ${ }^{1}$ Jovan Gardasevic ${ }^{1}$

'University of Montenegro, Faculty for Sport and Physical Education, Niksic, Montenegro

Correspondence: Ivan Vasiljevic (vasiljevic.ivan301@gmail.com)

Obesity today is a common chronic health problem that lowers quality of life and significantly affects morbidity and overall mortality. According to the World Health Organization, increasing obesity in children and adolescents is becoming a global health problem in both developed and developing countries. The aim of the study is to determine the level of nutrition by body mass index in female adolescents in Montenegro. The population in this study consisted of adolescents aged 15 to 18 years resident in the territory of Montenegro. The total sample of respondents is 771 female adolescents from secondary schools in Montenegro. Overweight is most prevalent in 15 -year-olds, while it is lowest in 
18 -year-olds. When it comes to obesity, it is most prevalent in 15 -yearolds and lowest in 17-year-olds. Overweight among female adolescents in Montenegro is less present than in other European countries.

\section{P20}

\section{ASSOCIATION OF FLEXIBILITY WITH SPEED AND AGILITY IN YOUTH FOOTBALLERS}

Fatjon Nurja' ${ }^{1}$ Kadri Hoxha ${ }^{2,3}$

'University of Shkodra, Department of Physical Education and Sports, Shkodra, Albania, ${ }^{2}$ SMART Sports Center , Tirana, Albania; 3School Shyqyri Peza, Tirana, Albania

Correspondence: Fatjon Nurja (fatjon_nurja@yahoo.com)

Scientific data on motor abilities in youth footballer are very important for the future higher training performance. The aim of this study was to find out if there were any correlation between flexibility with speed and agility in youth footballers. 36 male youth footballers (mean age - 17.2 years old) were assessed in this study for flexibility (sit \& reach test), speed (sprint $10 \mathrm{~m}$ and $30 \mathrm{~m}$ ) and agility (10x5m agility test). Bivariate Pearson correlation analysis was used to assess the relationships between tests measured in this study. Data for correlation coefficient show; flexibility with speed $(10 \mathrm{~m}) \mathrm{r}=0.145, \mathrm{p}=0.399$, flexibility with sprint $(30 \mathrm{~m}) \mathrm{r}=0.082$, $\mathrm{p}=0.633$ and flexibility with agility $(10 \times 5 \mathrm{~m}) \mathrm{r}=-0.036, \mathrm{p}=0.833$. Results for this study show that there was no statistical correlation between flexibility with speed and flexibility with agility. Data from this study suggest that further investigation are needed to find out more evidence for other motor abilities for possible correlation.

\section{P21}

\section{LEVEL OF ACTIVE LIFESTYLE AND EXERCISE APPROACH AMONG MALE AND FEMALE STUDENTS OF THE UNIVERSITY OF NOVI PAZAR DURING THE COVID-19 PANDEMIC}

\section{Dragan Bacovic ${ }^{1}$}

'University of Montenegro, Faculty for Sport and Physical Education, Niksic, Montenegro

Correspondence: Dragan Bacovic (dragan.b@ucg.ac.me)

The effect of temporary measures caused by the emergence of the COVID-19 virus has affected the limited movement and lifestyle change of the student population. This research aimed to determine changes in healthy lifestyle habits and the way of conducting the physical activity of students caused by the COVID-19 pandemic. The sample of respondents consisted of male and female students of the University of Novi Pazar in Serbia $(\mathrm{n}=68 ; 21.6 \pm 1.91$ age). This research used a survey questionnaire based on the assessment of healthy lifestyle habits. A review of the results can be concluded that $45.6 \%$ of students at the University of Novi Pazar regularly engage (at least three times a week) in some of the forms of sports and recreational activities, while $54.4 \%$ do not engage in regular physical activity. Male and female students consume healthier foods such as cooked meals $(74.5 \%)$ and fruits and vegetables (85.9\%). In addition to healthier products, students also consume products with much lower nutritional quality such as dough products (73.3\%), sweets (67.7\%), and snacks (56.9\%). Raising awareness of the importance of physical activity and healthy food habits can affect the prevention and correction of these problems and improve the mental health of students.

\section{P22}

\section{STUDENTS'S PHYSICAL ACTIVITY TO COVID19 EMERGENCY MEASURES IN SERBIA}

Jovan Vukovic' ${ }^{1}$ Nebojsa Maksimovic ${ }^{1}$, Zoran Milosević', Radenko Matic ${ }^{1}$, Ivana Milovanovic ${ }^{1}$, Milka Imbronjev' ${ }^{1}$, Damjan Jaksic ${ }^{1}$
'University of Novi Sad, Faculty of Sport and Physical Education, Novi Sad, Serbia

Correspondence: Jovan Vukovic (jovanvukovic@uns.ac.rs)

The emergence of coronavirus in Serbia led to the declaration of a state of emergency, which among other measures, included the lockdown of public life, organized sports, and regular daily physical activity. This study aimed to identify physical activity indicators for students from the University of Novi Sad before and during COVID-19 emergency measures in Serbia. The online survey has been carried out on a sample of 1764 students from the University of Novi Sad to determine respondents' physical activity. The statistical analysis was applied using confirmatory factor analysis and structural equation modeling in SPSS, AMOS 24.0. The obtained results show statistically significant changes in the daily routines of physical exercise students. The positive statistical significance of physical exercise habits for a better adaptation of students to new circumstances, i.e., better resistance to changes informed behavioral routines, was observed. This research data was collected within the research project with the title "Leisure time and physical activity of students of the University of Novi Sad during the COVID19 pandemic" (register number: 142-451-3098/2020-03), realized by the Faculty of Sport and Physical Education, University of Novi Sad, and financed by the Provincial Secretariat for higher education and scientific research. This research has been done in line with the COST Action's objectives (CA19101).

\section{P23}

\section{PHYSICAL ACTIVITY OF STUDENTS DURING THE COVID-19 PANDEMIC}

Marija Bubanja' ${ }^{1}$, Marina Vukoric ${ }^{1}$, Marin Corluka ${ }^{2}$

'University of Montenegro, Faculty for Sport and Physical Education, Podgorica, Montenegro, ${ }^{2}$ University of Mostar, Faculty of Mathematics and Science Education, Mostar, Bosnia and Herzegovina Correspondence: Marija Bubanja (marijabubanja@ymail.com)

It is well-known that physical activity is an important health determinant (Lee et al, 2012). This letter aims to identify the students' changes in exercising patterns caused by the COVID-19 pandemic. The sample in this study included 350 male students $22.49 \pm 2.21 \mathrm{yr}$, of the University of Mostar, Bosnia and Herzegovina. The basic criterion for the sample selection was the students' active involvement in sports at least three times per week before the temporary restrictive measures due to the COVID-19 pandemic were introduced. The survey was completed using Google Forms templates which were available on the website of the University of Mostar, during the period of May 5, 2020 - May 24, 2020. The obtained survey results were automatically exported to the Google spreadsheet. Data analysis was assessed using the SPSS 20 program (Chicago, IL, USA). Based on the results of the research, a decrease of a physical shape during the restrictive measures caused by the COVID-19 pandemic is evident in sports-active male students by $39.0 \%$. During the restriction measures, the most students spent exercising up to one hour daily $29.0 \%$. However, the time that the students spent exercising is satisfactory, but they have changed a style of exercising which could be associated with a decline in aerobic activity and insufficient intensity. Guidelines need to be found to prevent the consequences of insufficient physical activity.

\section{Publisher's Note:}

Montenegrin Sports Academy remains neutral with regard to jurisdictional claims in published maps and institutional affiliations. 